\title{
Ideas lingüísticas en Hispanoamérica: el modelo de Espinosa Pólit
}

\author{
Linguistic ideas in Latin America: the theoretical model of Espinosa Pólit
}

Alfonso Zamorano Aguilar

Universidad de Córdoba, Facultad de Filosofía y Letras, Área de Lingüística General, Córdoba, España.

Correo electrónico: fe2zaaga@uco.es

Este artículo se constituye como una contribución a una línea de investigación abierta recientemente sobre la recepción de las ideas lingüísticas en Hispanoamérica (cuyo estudio suele suponer una reestructuración y/o una ampliación de la historia de las ideas lingüísticas españolas) y sobre la historificación de la idiosincrasia y originalidad del desarrollo del pensamiento lingüístico en América Latina y, en concreto, en Ecuador, país que aún no había sido abordado por la bibliografía historiográfica. El estudio específico de la obra de Espinosa Pólit pone de relieve la presencia en Ecuador de (1) conceptos modernos sobre base tradicional; (2) una línea ecléctica de reflexión gramatical y (3) una transposición didáctica de signo distinto al que las historias de la lingüística se refieren, por ejemplo, en el caso de la RAE, de Eduardo Benot o de Bello.

Palabras clave: historia de la lingüística, Ecuador, Espinosa Pólit, ideas lingüísticas en Hispanoamérica.

This article is a contribution to a recent research perspective on the reception of linguistic ideas in Latin America (whose study usually involves a restructure and/or an extension of the history of Spanish linguistic thought); and it is also a study of the originality on the development of linguistics in Latin America and, specifically, in Ecuador, which has no presence in the bibliography of the history of linguistics. The concrete study of Espinosa's grammar (1) customizes modern concepts based in tradicional theories; and (2) highlights the development of an eclectic grammatical reflection and (3) its didactic transposition in a different sense of the well-known history of Spanish grammar, for example, in the case of RAE, Benot or Bello.

Key words: history of linguistics, Ecuador, Espinosa Pólit, linguistic ideas in Latin America.

\section{Presentación}

Con el presente artículo pretendemos cubrir un doble propósito:

a) Contribuir a la historificación de la gramática en la América hispánica, línea de trabajo que cuenta con algunos estudios, para países como Uruguay, Argentina, Cuba, Chile, Colombia, entre otros, gracias a las recientes investigaciones de Calero Vaquera (2008b, 2009b y 2010), García Folgado (2010), Sinner (2010), Zamorano 
Aguilar (2005, 2008a, 2010a y 2010b) y Montoro del Arco-Zamorano Aguilar (2010). A este nuevo panorama de la crítica lingüística habría que añadir los trabajos pioneros de Rabanales (1978), Parodi (1981), Lope Blanch (1989), Kovacci (1991), Álvarez Martínez (1994) o, incluso, Sueiro Justel (2002), entre otros. Nuestro artículo pretende ir completando este panorama y ampliarlo a Ecuador.

b) Perfilar y desarrollar la repercusión de la teoría y la praxis analítica en la gramática escolar, en la línea de los estudios del grupo ANAGRAMA [HUM2007-60976/FILO], con el fin de ir completando la constitución de la actual reflexión sintáctica mediante el estudio de la recepción en América y específicamente en Ecuador, del análisis lógico y análisis gramatical durante la primera mitad del siglo XX.

El texto base de nuestra investigación será el Resumen sintético de análisis gramatical y lógico de Aurelio y José Espinosa Pólit, publicado en Quito por la Editorial Ecuatoriana en 1949, aunque se establecerá una comparación con la serie textual de Aurelio Espinosa en materia gramatical (Hassler 2002).

En cuanto al enfoque metodológico que se empleará para esta investigación será mixto, de historiografía lingüística interna y externa. Y esta elección se justifica por el hecho de que, en la lingüística actual, una investigación en el ámbito de la historia e historiografía de la lingüística, con una base metodológica adecuada, según nuestro criterio, debe perseguir, ante todo:

(1) el acercamiento al texto, autor o ideas analizadas desde una óptica contextualizada, atendiendo a las coordenadas socio-espacio-culturales en que se gestó, con el fin de lograr una explicación depurada y ajustada de su ubicación en la historia del pensamiento lingüístico, su lugar en el canon (tanto histórico como historiográfico, cf. Zamorano Aguilar 2008b y 2009) y su proyección en la lingüística actual, así como sus fuentes teóricas y metodológicas; a esta vía de análisis se viene denominando historiografía de la lingüística externa (cf. Brekle 1986).

(2) Además, es conveniente acometer un estudio detallado de las ideas gramaticales, lexicográficas o, en general, lingüísticas en el seno de la teoría del autor o de la estructura teórica en que se localiza el texto o la idea lingüística. Para ello, son de utilidad instrumentos cuantitativo-estadísticos, modelización de las teorías, así como su conexión desde presupuestos teórico-lingüísticos y metodológicos actuales. Esta segunda vía de análisis responde al nombre de historiografía de la lingüística interna (cf. Brekle 1986).

\section{El AUtor (AUTORES) DE LA OBRA}

Los autores del texto son José y Aurelio Espinosa Pólit, hermanos. Del primero apenas tenemos datos de su bio-bibliografía. Sin embargo, el segundo es considerado como uno de los intelectuales más destacados de Ecuador en el primer tercio del siglo XX. El Resumen sintético, aunque firmado por ambos hermanos, parece ser obra de Aurelio Espinosa, tal y como se recoge en algunos documentos de orden gramatical, a partir del estudio de Corrales (2006) sobre el pensamiento de Aurelio Espinosa Pólit. Vamos, pues, a partir de esta hipótesis en relación con la autoría.

Aurelio Espinosa Pólit nació el 11 de julio de 1894 en Quito (Pichincha) y murió el 21 de enero de 1961 en su ciudad natal. Hijo de Aurelio Espinosa Coronel (abogado y político conservador) y Cornelia Pólit Lasso, su infancia y juventud transcurrieron fuera de su país natal, debido al exilio de su padre, desterrado por el presidente de la 
república Eloy Alfaro, tras la revolución liberal. Así, su formación académica inicial (primaria, secundaria y bachillerato) se desarrolló entre Francia, Suiza, Bélgica (Namur) e Inglaterra.

Estudió Letras y Filosofía en España, en el Colegio Máximo de Granada; y Teología en el Colegio Máximo de Sarriá. Además, terminó la carrera de Estudios Clásicos en Cambridge (Inglaterra).

Su formación religiosa comenzó con su ingreso en la Compañía de Jesús en 1911, y se ordenó sacerdote el 31 de diciembre de 1924, en Barcelona. Entre 1918 y 1921 enseñó latín y griego en la casa de probación de Granada y geografía e historia en el colegio de Chamartín de Madrid (1921-1922) (Villalba-Baptista 2011: 1).

En el año 1928 vuelve a Ecuador y, desde su llegada, su afán principal es la dedicación a la enseñanza de "las lenguas y literaturas clásicas, al cultivo de las letras castellanas y de la poesía, a la traducción de los grandes autores griegos y latinos. También la cultura y la literatura de su patria fueron objeto de su atención y desvelos" (AA.VV. 1961: 270).

Como impulsor de la cultura en Ecuador se le atribuye el Instituto Superior de Humanidades Clásicas de Cotocollao, donde fundó la Biblioteca Ecuatoriana (biblioteca, hemeroteca y museo). Por otro lado, fue rector de la Universidad Católica del Ecuador desde su fundación, en 1946. Asimismo, fue miembro de la Academia Ecuatoriana (1933) y correspondiente de las Academias española, colombiana y mexicana. Impartió conferencias en varios centros culturales de importancia de su país natal, como el Instituto Caro y Cuervo (1956). "Durante el gobierno del Dr. Carlos Alberto Arroyo del Río fue miembro de la comisión que debía editar, en 50 volúmenes, los "Clásicos Ecuatorianos", pero luego de la revolución del 28 de mayo de 1944, y con el advenimiento del segundo velasquismo, dicho programa fue suspendido y sólo se alcanzaron a editar cinco tomos" (Avilés Pino s.f.: en red).

Su producción investigadora y docente abarca temas diversos: estudios grecolatinos (sobre todo, Virgilio y Sófocles), historia y cultura del Ecuador, ediciones críticas de autores ecuatorianos, pedagogía y obras apologéticas.

Consideramos que la prolija labor de Aurelio Espinosa quedó bien sintetizada en 1956 por el director del Instituto Caro y Cuervo, José Manuel Rivas Sacconi:

Hacer una presentación del Reverendo Padre Aurelio Espinosa Pólit S. I. no es misión de fácil desempeño. La exposición de sus actividades de educador, de promotor de la cultura, de fundador de bibliotecas, de apóstol, de escritor; el análisis de su obra múltiple como editor de autores ecuatorianos, como traductor de los poetas clásicos y teórico de este tipo de traducción, como creador original de poesía, como crítico, como profesor, exigiría toda una serie de conferencias, un estudio intenso de sus muchos libros (AA.VV. 1956: 431).

Desde el punto de vista de su pensamiento filosófico y literario (lo que da muestra de su concepción de las letras y de las humanidades) aparece rotulado por uno de sus biógrafos y comentadores, Arturo Andrés Roig, como "vitalismo, organicismo e intuicionismo" (Roig 1980: 65-69). Sus ideas estético-religiosas

habían de condicionar inevitablemente su comprensión de la filosofía. Esta, prolongando posiciones que venían dadas dentro del espiritualismo francés del siglo XIX, será entendida fundamentalmente como una psicología, que gira toda entera, en este caso, sobre el problema del destino. Dentro del espiritualismo francés ecléctico, Teodoro Jouffroy, sin 
duda su representante más fino y de mayor valor filosófico, había centrado la filosofía en una psicología que giraba, precisamente, sobre el mismo tema.

Mas, el vitalismo organicista e intuicionista, no sólo lo afirmó en su psicologismo espiritualista, sino que le condujo a considerar que la literatura era la vía de expresión y manifestación más rica y directa de la vida (Roig 1980: 71).

Para Espinosa la literatura (y, más específicamente, la poesía lírica) era el instrumento que permitía al ser humano penetrar en el "conocimiento interno de la realidad del alma del hombre y de los pueblos” (Roig 1980: 72). Así, la filosofía se subordinaba a la literatura, incluso en la escuela, como saber auxiliar de esta. De esta manera, "venía a quedar desvalorizado el importante lugar que, siguiendo la tradición balmesiana, se había concedido a la filosofía como "ideología", en el sentido de una lógica y una psicología genética de las ideas" (72-73).

Roig (1980: 73 y ss.) encuentra en Husserl y en Bergson algunas claves del pensamiento filosófico y estético de Espinosa, aunque la relación no es directa. Del primero, el "imperativo de "ir hacia las cosas mismas"”; del segundo, el "interiorizarnos en el 'yo profundo' en busca de los 'datos inmediatos de la conciencia”" (ibidem). Es una fundamentación de esa "psicología introspectiva metafísica" que parece estar en la base del pensamiento de Espinosa Pólit.

\section{Algunas claves de contexto}

\subsection{La educación en Ecuador en la primera mitad del XX}

Por cuestiones históricas, la educación en Ecuador -como en muchos de los países latinoamericanos- comienza a desarrollarse gracias a la labor de la Iglesia y sus misiones. Así, fueron los franciscanos los que en 1553 fundaron la primera escuela en Quito, llamada San Andrés. Y en 1596 la primera universidad: San Fulgencio (García Muñoz 2003: 3). Los jesuitas tuvieron en este desarrollo y en la posterior implantación de planes de estudio una importancia capital en el país ${ }^{1}$.

La presidencia de Vicente Rocafuerte (1835-1839) y, posteriormente, la de García Moreno (1861-1865) supondrán para Ecuador un impulso importante del progreso del pensamiento y de la importancia de y la confianza en la educación en el desarrollo del país ${ }^{2}$. Si Rocafuerte supuso un gran avance cultural para Ecuador, con García

\footnotetext{
"La presencia de los jesuitas en el Ecuador, fue muy apreciada, ellos llegaron en 1568 a las colonias españolas en América. Sobresalieron indudablemente en el campo educativo, para este tiempo la educación era tarea exclusiva de la Iglesia, y los jesuitas supieron ganarse un lugar de privilegio y consideración. Fundaron en Quito el Colegio de San Luis en 1568, fue la primera institución de esta rama creada en esta ciudad, y la Universidad de San Gregorio en el año 1622, destinados a la formación de los criollos. Los jesuitas se extendieron por los dominios de la corona española y trabajaron para que estos progresen. En 1755 la imprenta llegó a la Real Audiencia, ubicándosela en Ambato, donde los jesuitas tuvieron autoridad sobre ella; lo que dio inicio a divulgar los textos que en ese periodo se utilizaron. La expulsión de estos padres en 1767 provocó, en nuestro territorio, un desajuste en la educación de los criollos [sic]" (García Muñoz 2003: 4).

2 La independencia de Ecuador y su adhesión a la Gran Colombia, se produce el 24 de mayo de 1822. En diciembre de 1829 Simón Bolívar dictó un decreto por el que se reorganizaba la administración de las universidades y se reforzaba la instrucción pública en concordancia con la religión católica, que era la mayoritaria en Ecuador. Y a partir de 1830, Ecuador se organiza como una república y en las constituciones y leyes sucesivas se defiende la necesidad de promover la instrucción pública.
} 
Moreno se afianzó la fuerza e impronta del catolicismo en el país, de ahí que las reformas educativas se dejaran en manos de congregaciones religiosas.

Sin duda alguna, el período de García Moreno se constituye como la etapa de la historia educativa ecuatoriana donde los ideales de los jesuitas pudieron alcanzar cotas más elevadas. Su acción educativa era muy valorada, sobre todo, por los sectores más conservadores y católicos y, en cambio, menos alabada por liberales y laicistas (Delgado Criado 1994: 513). Expulsados de casi todos los países hispanoamericanos a partir de 1848 (en Argentina), para el caso del Ecuador, tras su salida en 1852, vuelven al país en 1862, bajo la presidencia de García Moreno, donde encontraron el escenario político más favorable para desarrollar su proyecto de educación. Y aunque con el asesinato en 1875 de García Moreno no pudieron desplegar con plenitud su obra, puede afirmarse que, en su proceso de acomodación a cada nación y sistema político, intentaron defender algunas de sus señas de identidad ${ }^{3}$.

El año 1884 es clave para entender el devenir histórico del sistema educativo ecuatoriano. En este año se crea el Ministerio de Instrucción Pública que organizaba y administraba las diferentes instituciones dedicadas en Ecuador a la educación. En 1890, durante el gobierno de Antonio Flores (1833-1915), se aprobó un importante proyecto de ley orgánica de educación, que suponía una reforma signficativa de la metodología y la educación en el país, con la implantación de técnicas y tendencias de corte europeo ${ }^{4}$. Es una etapa política en la que se intentó conciliar la tradición católica con los nuevos vientos de orientación liberal.

Aun así seguían existiendo diferencias notables entre la educación pública (con carencias y dificultades) y la elitista educación privada, en manos de la Iglesia. Habrá que esperar a la constitución de 1906, bajo los gobiernos de Eloy Alfaro (18421912) entre 1895-1901 y 1906-1911 para alcanzar la separación Iglesia-Estado, libertad de enseñanza, supresión de religión oficial, etc. Habrá que esperar a 1938 para que las universidades pudieran tener autonomía en su funcionamiento interno y administrativo.

Entre 1930 y 1940 se divulgan las ideas socialistas tanto en el país como en el Ministerio de Instrucción Pública (García Muñoz 2003: 16). De forma que la situación del país, en materia educativa, está totalmente cambiada hacia 1950.

A la luz de estos datos, podremos observar, en lo que sigue, cómo el texto de Espinosa (jesuita, intelectual, pedagogo y académico) es fruto del devenir histórico de su país. Ello permite que el texto pueda ser considerado, historiográficamente, como relevante de su contexto socio-cultural y político-legislativo. Este marco se constituye, como intentaremos demostrar en lo que sigue, en el elemento externo fundamental que justifique la interpretación historiográfica de la obra y de las decisiones teórico-prácticas de Espinosa en su obra.

Esta se concretaba en: “esmerada educación moral y religiosa, la atención a la formación humanística y filosófica, los ejercicios prácticos, los medios de emulación y los brillantes actos públicos” (Delgado Criado 1994: 515).

4 “El proyecto consultaba para la enseñanza secundaria la adopción del método concéntrico de Ferry, que aunque obstaculizaba los estudios, proporcionaba elementos generales que podrían desenvolverse después. Para la enseñanza suprema insinuaba el método alemán que combinaba el oral y escrito para grabar mejor las ideas en los alumnos. En lo que respecta a la enseñanza primaria insistía en que esta debe ser obligatoria y gratuita a todos los ciudadanos porque "Leer, escribir, contar y los principios generales de la moral son, decía conocimiento que debe poseer todo elector", en un país democrático [sic]" (García Muñoz 2003: 13). 


\subsection{Análisis lógico y gramatical: desarrollo hasta 1950}

Las relaciones entre lógica/filosofía y gramática han sido extraordinariamente fructíferas a lo largo de la historia del pensamiento lingüístico. En este diálogo epistemológico se localiza toda una tradición que abarca desde los modalistas medievales hasta los gramáticos-filósofos franceses del XVIII y del XIX (J. Harris, Du Marsais, Beauzée, Condillac, Destutt, etc.) (ver Calero 2008a y Sinner 2009), pasando por el Brocense y Port-Royal y sus seguidores.

Uno de los frutos de esa conexión disciplinar son las relaciones entre análisis lógico y análisis gramatical, cuyo nacimiento se produce con U. Domergue y su Grammaire françoise simplifié (1778) (continuado luego por Du Marsais, 1797) y, como afirma Calero (2009a: 27) a través de Chervel (1977: 178), “ampliamente seguido en la práctica escolar francesa (y española) a lo largo de siglo y medio hasta su reducción progresiva a un único tipo de análisis (gramatical) en donde terminarán por subsumirse los conceptos lógicos". El tratado de Espinosa Pólit que estudiamos en este artículo es una pieza más del puzzle, donde los conceptos lógicos devienen en lingüísticos y, específicamente, sintácticos, aunque la mezcla de lo lógico y lo gramatical se lleva a cabo de forma singular y tamizada por la trasposición didáctica de la teoría (Chevallard 1991; cf. etiam López Ferrero 1997) y la opción científica de Espinosa, según intentaremos demostrar seguidamente.

En origen, analizar era diseccionar el pensamiento a través del lenguaje, según el empirismo de Condillac (1789 [1775]: 159): "Le premier objet du langage est donc d'analyser la pensée". En esa disección o descomposición se caminaba desde lo más complejo (perceptible) hasta lo más simple (no perceptible), de ahí que los procedimientos de doble análisis tan comunes desde el Brocense y, luego, muy presentes en Port-Royal o Harris, desemboquen, incluso, en el doblete estructura profunda/estructura superficial del modelo estándar de la gramática generativa de Chomsky, cuyos precedentes expuso el propio autor en su Cartesian Linguistics de 1966.

Esta práctica del análisis lógico/análisis gramatical va a encontrar en la didáctica un terreno propicio para su desarrollo, sobre todo, a partir de principios del siglo XIX, con las renovadoras doctrinas pedagógicas de los ideólogos. En Francia, como indica Chervel (1977: 72), serán Domergue, Thurot, Sicard, Thiébault y Destutt los pioneros en la gramática escolar de su país ${ }^{5}$.

Por lo que respecta a la tradición gramatical española, el origen y desarrollo de la práctica del análisis lógico y el análisis gramatical habría que situarlo en Cristóbal y Jaramillo “quien en su Arte nuevo de ortología, gramática castellana... (1793) utiliza un patrón de análisis oracional -exclusivamente morfológico- que recuerda vagamente al que empleará unos años después Letellier en su edición revisada de la Grammaire françoise de Lhomond (1805)" (Calero 2008a: 22). Aquí, en realidad,

\footnotetext{
Las sucesivas y múltiples ediciones de la considerada primera gramática escolar francesa, la Grammaire françoise (1780) de Lhomond, a su muerte revisada y aumentada por Letellier, irán incorporando paulatinamente presupuestos de la gramática general del XVIII (como el concepto de 'elipsis' o el ejercicio de 'análisis lógico'). Pero será la Nouvelle grammaire françoise (1823) de Noël y Chapsal la obra que inaugure el 'siglo de oro' de la gramática escolar en Francia, vulgarizando la teoría sintáctica tanto de los primeros gramáticos filósofos como de los ideólogos, estableciendo el canon de la corriente escolar al oficializar y fijar los consabidos términos del análisis lógico y gramatical (p. ej., complemento, oraciones principales e incidentes, etc.) (Calero 2009a: 32).
} 
habría que localizar los primeros vestigios del "análisis", pues sigue una senda muy tradicional de corte greco-latino y medieval.

Habrá que esperar hasta Jovellanos (1924 [¿1795?]) para localizar un análisis más moderno, en la línea de Condillac. En 1799 Muñoz Álvarez retoma el análisis lógico y gramatical de Du Marsais, considerándose así como el primer ejemplo de este doble análisis en español ${ }^{6}$.

Sin embargo, los dos autores que la crítica (cf. Calero 2008a) señala como fieles transmisores del análisis lógico y gramatical del país vecino son Juan Calderón (1843) (vid. Calero 2008a; Calero-Zamorano 2010) y Merino (1843) (vid. García Folgado-Montoro 2008; Calero-Zamorano 2010). En ambos, se aprecia de forma acabada, coherente y consciente la práctica del doble análisis de Du Marsais. En el caso de Merino, nos encontramos ante el "primer manual destinado específicamente a la práctica escolar de este método [analítico]" (García Folgado-Montoro 2008) ${ }^{7}$.

El caso de Hispanoamérica (no sólo en las relaciones análisis lógico y gramatical, sino, en general, desde la historiografía de la lingüística) está siendo desde hace pocos años objeto de investigación. Aunque la información de que disponemos, por países, se encuentra bastante desequilibrada, sabemos que en Argentina, por ejemplo, la doctrina de Locke, Condillac o Destutt se difundía desde principios del XIX. Aquí se afinca la Gramática española de Felipe Senillosa (1817) (cf. García Folgado 2010) ${ }^{8}$. Autores que habría que destacar en este continente son: Antonio J. Valdés (1817), José Codina (1821), Rufino y Pedro Sánchez (1828) o peninsulares como Herranz y Quirós (1836). Merece la pena destacarse también a Vicente García Aguilera y su Tratado de análisis lógico y gramatical (1880), en la senda de Juan Calderón (cf. Calero 2008a). De época cercana es el Curso gradual de gramática castellana (c. 1884) de José Hidalgo Martínez (cf. Calero 2009b).

El caso de Uruguay ha sido investigado, sobre todo, en la primera mitad del siglo XX, con los tratados de Gámez Marín, dedicado a Benot y siguiendo su senda teórica (cf. Zamorano 2005). Asimismo, los tratados escolares de Abadíe-Zarrilli (cf. Zamorano 2008a; Montoro del Arco-Zamorano 2010) ponen de manifiesto la presencia del intelectual gaditano en la educación primaria y secundaria.

El caso de Cuba cuenta ya también con algunos trabajos relevantes. "Como en otros territorios hispanoamericanos, también en Cuba los años finales del siglo XVIII y principios del XIX son testigos de la llegada a los círculos intelectuales progresistas

La trascendencia de este análisis se observa en los seguidores que tendrá: Saqueniza (1828) (quien sustituye los términos de etimología/analogía por el de análisis), Lacueva (1832), Amézaga (1836), Noboa (1839) o Martínez López (1841). Todos ellos aportarán variantes y desarrollos del original francés.

Estamos de acuerdo con Calero (2010: 72) cuando afirma que a la "proliferación de tratados de análisis del español contribuyó también la legislación educativa de la época, que con una serie de medidas oportunas ofreció el caldo de cultivo propicio para esta fecunda práctica". El primer texto legal que defiende esta práctica didáctica, como han investigado García Folgado-Montoro (2008a), fue el Reglamento de Escuelas Públicas de Instrucción Primaria (26 de noviembre de 1838), así como, posteriormente, la Ley Moyano de 1857 (en vigor hasta 1970).

8 “Al igual que para Du Marsais, Condillac o Destutt, para Senillosa el análisis es el instrumento que permite acceder a cualquier tipo de conocimiento, también al de la gramática de las lenguas ("Mi objeto ha sido presentar la gramática baxo un órden analítico, yendo por grados de lo conocido y bien entendido à lo por conocer", Senillosa 1817: III). Sin que en su obra aparezca el clásico desdoble del análisis en su aspecto lógico y gramatical, es fundamentalmente al análisis lógico (= la descomposición de la proposición) hacia el que Senillosa dirige su atención, puesto que para él las palabras no son sino la "parte mecánica" (64) del idioma, en contraste con las ideas, que son "el verdadero ser de la palabra" (I)" (Calero 2010: 75-76). 
de las teorías empiristas de Bacon y Locke, del sensualismo de Condillac y de la Ideología abanderada por Destutt de Tracy" (Calero 2010: 80). Merece destacarse Juan Justo Reyes y sus Principios analíticos (1838), deudor de Félix Varela, intelectual destacado en Cuba que sigue la doctrina teórica de Destutt, Condillac y Du Marsais.

En lo que a Chile respecta, al margen de estudios sobre Bello o Lenz, en el ámbito del análisis lógico y gramatical, merece destacarse en el siglo XX a Julio Meza y su Gramática castellana (1942) y su Análisis lógico (1944) (cf. Sinner 2010), dos de los pocos textos chilenos investigados por los especialistas en análisis lógico y gramatical.

También en Perú, Venezuela, Colombia o Ecuador hemos localizado huellas de la práctica del análisis lógico y gramatical. Además, y como podemos observar, por ejemplo, por el Compendio del tratado teórico-práctico de la lengua castellana de los Hermanos de las Escuelas Cristianas (París, 1899, y con difusión en Ecuador), las órdenes religiosas desempeñaron un importante papel de difusión (no siempre original) de las ideas lingüísticas, dado que la gramática formaba parte de los planes de estudio de los seminarios e instituciones educativas dirigidas o tuteladas por dichas órdenes o congregaciones de tipo religioso. El tratado de Espinosa Pólit es un ejemplo más de esta difusión en el ámbito de la educación pública y privada, manejada (según el período histórico y la época) por la Iglesia.

\section{RESUMEN SINTÉTICO DE ANÁLISIS LÓGICO Y GRAMATICAL (1949): ESTRUCTURAS EXTERNA E INTERNA. FUNDAMENTOS Y CANON}

El prólogo de la obra (1949: 3-11) está fechado en Cotocallao el 27 de septiembre de 1948. En él aparecen ya algunos principios teóricos, metodológicos y didácticos del contenido que aborda:

a) considera que el análisis es una actividad propedéutica para los estudios clásicos (latín y griego);

b) apela a la trasposición didáctica de la teoría para justificar ausencias o manipulaciones de los datos o de los conceptos, lo que pone de relieve el rigor y método en el desarrollo de la teoría lingüística y, por el contrario, la menor atención a cuestiones pedagógicas, aunque estas suelen estar presentes en todo el texto.

c) considera que el análisis no es incompatible o sustitutivo de la gramática, aunque deducimos rasgos propios de cada uno. Así, la gramática parece calificarse como descriptiva y normativa de la lengua; por el contrario, el análisis ahonda en la explicación de los fenómenos lingüísticos, en sus funciones y en su lógica interna;

d) Tras una exposición pedagógica sobre la planificación de la enseñanza del análisis, Espinosa señala que mientras que la analogía (morfología) y el vocabulario (lexicología) de cada lengua son rasgos diferenciales de cada una de ellas, la sintaxis (lo que luego Chomsky denominará la "estructura profunda") es común a todas las lenguas, aunque las "formas externas" (8) (lo que el fundador del generativismo llamaría "estructura superficial") sean diferentes según las lenguas". El objeto del análisis, como método y disciplina, es el estudio de esas estructuras profundas. Espinosa se inserta así en toda una tradición de corte racionalista (y nos encontramos

\footnotetext{
"De estos tres elementos del idioma [analogía, sintaxis y vocabulario], dos son necesariamente exclusivos en cada uno de ellos: la analogía y el vocabulario; y uno es, en parte al menos, común a todos: la sintaxis. Decimos: ‘en parte al menos', porque las formas externas de las construcciones sintácticas están también diversificadas en las diversas lenguas; pero el sentido, el valor, la esencia íntima de estas construcciones de la sintaxis, es común a todas" (8).
} 
ya en 1948/1949) que se remonta a los modistas, continúa -con muchos maticesen el Brocense, Escalígero, Harris, etc. y llega hasta las corrientes actuales de corte cognitivo y generativo, con todas las diferencias que el cambio de paradigmas provoca.

Vemos, pues, que el concepto de "análisis", aunque está muy derivado hacia el terreno lingüístico, conserva aún mucho de su primitivo valor lógico, al menos, en la formulación general del enfoque, pues el desarrollo de cada tipo de análisis (gramatical y lógico) pone de relieve que este método o práctica es de tipo exclusivamente lingüístico, aunque se juega con dos niveles de la lengua: el abstracto y atomicista (análisis gramatical, que se concreta luego en morfología y semántica particulares), y el abstracto pero integralista de la lengua (análisis lógico, que profundiza en la sintaxis de la estructura profunda de cada sistema). Podríamos decir que ahora análisis se constituye como una teoría de la morfosintaxis de la lengua y de las lenguas, dependiendo de su aplicación.

El texto se divide en cuatro partes de extensión variable: 1) que dedica al concepto y tipos de análisis; 2) análisis gramatical; 3) análisis lógico de palabras; 4) análisis lógico de oraciones.

El análisis se define como "el ejercicio mental por el cual se aíslan, para conocer su valor, los elementos de una frase" (13). Observamos que esta definición del análisis conecta con una tradición que podemos remontar a Jovellanos o, en el siglo XIX, a Saqueniza y Noboa, al menos, en las actividades del análisis, no en las fases que estos autores distinguen. La fase de "síntesis" está ausente en el programa de Espinosa, quizá debido a que el peso lógico deja paso al lingüístico en su tratado:

El análisis se divide en dos tipos: a) gramatical: "el que aísla las palabras consideradas como elementos del lenguaje, y analiza en ellas la naturaleza y accidentes de cada una de por sí" (13); b) lógico: "el que aísla las palabras o las frases, y analiza en ellas el valor que adquieren por estar relacionadas entre sí" (14). El lógico, a su vez, se divide en: 1) análisis lógico de palabras: "el que examina las relaciones de un término respecto de otro, dentro de una misma oración" $(14) ; 2)$ análisis lógico de oraciones: "el que examina las relaciones de una oración respecto de otra, dentro de una misma frase" (14). Establece una distinción entre "frase" y "oración"; la primera tiene sentido completo; la segunda, no.

En el análisis gramatical distingue nueve partes en "el lenguaje" (según la terminología de Espinosa): sustantivo, artículo, adjetivo, pronombre, verbo (estas cinco son las variables) y preposición, conjunción, adverbio e interjección (invariables). Las variables pueden sufrir los siguientes accidentes (variaciones): género, número, persona, tiempo, modo, voz y caso. De este último indica:

El caso es la variación en la desinencia de las palabras declinables, para indicar su oficio lógico (cf. n. 76). Esencial en la lengua madre, el latín, no ha dejado huella en castellano sino en los pronombres personales (v. g.: yo, me, mí), y en el cuyo relativo (26).

Por "oficio lógico" entiende Espinosa "la relación específica de dependencia de un término respecto de un verbo, o respecto de otro término de la misma oración" (41). Además, el autor introduce de forma hábil el concepto de "equivalencia lógica" para sugerir una conexión entre cada parte analizable de la oración (sustantivo, adjetivo, pronombre) y aquella función lógica que tenía en latín. Así, el "nominativo" equivale al sujeto o atributo y el "genitivo" al complemento determinativo y así sucesivamente. 
En cuanto a las categorías gramaticales que se distinguen en el Resumen sintético de 1949, estos son los datos que se extraen del texto:

\begin{tabular}{|c|c|}
\hline Sustantivo & “palabra que designa toda clase de seres” (1949: 18). \\
\hline Artículo & $\begin{array}{l}\text { "palabra que se antepone al sustantivo, o a cuanto haga oficio } \\
\text { de tal, para determinarlo ligeramente, aunque a veces lo deja } \\
\text { indeterminado" (19). }\end{array}$ \\
\hline Adjetivo & $\begin{array}{l}\text { "palabra que se junta al sustantivo para precisarlo de alguna } \\
\text { manera calificándolo o determinándolo" (21). }\end{array}$ \\
\hline Pronombre & $\begin{array}{l}\text { "palabra variable que reemplaza al sustantivo (y, a veces, al } \\
\text { adjetivo, al adverbio, y aun a oraciones)" (25). }\end{array}$ \\
\hline Verbo & $\begin{array}{l}\text { "palabra conjugable que expresa acción, pasión o existencia de } \\
\text { los seres, o que ayuda a la conjugación de otros verbos" (28). }\end{array}$ \\
\hline Adverbio & $\begin{array}{l}\text { "palabra invariable que modifica el sentido del término a que } \\
\text { se junta" (33). Se habla de "adverbios ideológicos" (= de } \\
\text { afirmación, duda, negación y ponderación). }\end{array}$ \\
\hline Preposición & $\begin{array}{l}\text { "palabra invariable que determina el oficio del término a que se } \\
\text { junta, dándole el régimen que le corresponde. Este término puede } \\
\text { ser: un sustantivo, un adjetivo, un adverbio circunstancial, una } \\
\text { oración, o también un pronombre que corresponde a cualquiera } \\
\text { de los casos anteriores" (35). }\end{array}$ \\
\hline Conjunción & "palabra invariable que une dos términos u oraciones" (36). \\
\hline Interjección & “palabra invariable que indica alguna emoción” (38). \\
\hline
\end{tabular}

En el análisis lógico se introduce un concepto que recuerda al moderno "sintagma". Se trata del "término", entendido como "una palabra o agrupación de palabras que tiene determinado oficio en la oración" (1949: 40).

Las únicas palabras analizables, o sea, con oficio lógico son el sustantivo, el adjetivo, el pronombre y el participio. Ni el verbo ni las partes invariables lo son. Así, el valor lógico del verbo es su clasificación en tres grupos: unipersonales ${ }^{10}$ (ej. Anochece), sustantivo ("el que une un sujeto con un atributo para formar un juicio" (1949: 54); ej. Yo soy un pobre escudero) y atributivos (recuerda incluso la teoría del verbo único, aunque señala que ya está en desuso), ej. Yo corro por el campo (intransitivo) o Digo algo a Luis (transitivo).

Por lo que respecta al análisis lógico de oraciones "es el que examina las relaciones de una oración respecto de otra DENTRO DE UNA MISMA FRASE" (61). A pesar de que habla de "frase" y antes, además, la ha definido, ahora parece olvidarse de este concepto y se refiere solo a: a) idea: "representación que la mente conserva de un objeto o de un ser percibidos, y que le sirve para expresarlos con palabras" (62);

10 Habla de "impropiamente unipersonales" cuando se refiere al verbo haber. Ej. Hubo desmayos. 
b) oración: "palabra o conjunto de palabras que relacionan entre sí varias ideas, y forman un concepto por lo menos parcial" (62); c) cláusula: "conjunto de oraciones que forman un concepto complejo, siempre cabal" (62).

Distingue Espinosa Pólit cuatro tipos de valores lógicos: a) oficio lógico: “expresa las relaciones que existen entre unas oraciones y otras (independientes, subordinadas o cosubordinadas) (65); b) forma gramatical: "expresa el modo como se juntan las oraciones entre sí (por conjunciones, o relativos, o modos verbales" (65); c) modo lógico: "el modo lógico expresa el orden de cosas en que se considera lo enunciado (orden real, hipotético o irreal)" (66); d) forma lógica: "expresa las diversas modalidades con que puede enunciarse la idea del verbo (ya sea afirmándola o negándola; ya sea prohibiendo, deseando, exhortando, interrogando o exclamando) (66).

Se podría decir que oficio lógico y forma gramatical por un lado, y modo lógico y forma lógica por otro, se corresponden, respectivamente, con lo que podemos llamar modernamente el dictum y el modus. Habría una operación lógica (oficio lógico y modo lógico) y una operación lingüístico-gramatical (forma gramatical y forma lógica), al estilo del racionalismo port-royalista.

Como puede observarse, Espinosa realiza una interpretación personal y algo caótica de la tradición. Son muchas las fuentes que pueden sentirse de forma latente en las definiciones y clasificaciones establecidas en el análisis gramatical, lo que pone de relieve, como en otros muchos gramáticos escolares, la existencia de un canon de lecturas ecléctico (vid. Zamorano 2009). Así, en las nueve partes de la oración encontramos la huella de Jovellanos, de Suárez o de la GRAE de 1920. A Suárez y Fandiño lo podemos observar en las definiciones del sustantivo y del adjetivo (Calero 1986). A Salvá y a Bello ${ }^{11}$ en el adverbio y en la preposición, respectivamente. A la tradición gramatical racionalista pura (incluso Port-Royal) y, en el polo opuesto, la tradición nebrisense las podemos observar en aspectos tan contrapuestos como la consideración de la estructura oracional a partir del verbo sustantivo (Espinosa usa este término para referirse a ser) y el concepto de "caso" al estilo de la gramática renacentista de las lenguas vernáculas. Sorprende, sin embargo -aunque es, por otra parte, muy coherente- la escasa atención que presta a la gramática académica, a pesar de que, como sabemos, Espinosa la conocía en profundidad. Indica Roig (1980: 12) que, como escritor, usaba con frecuencia el diccionario de la RAE, que tenía encima de su mesa de trabajo.

La distinción entre análisis gramatical (morfo-semántico de las partes de la oración) y lógico (sintáctico-funcional) parece trasvasarse a los criterios empleados. Así, las unidades "analizables" (en terminología del propio Espinosa) siguen una definición nocional, acorde con el enfoque post-modistae de conexión entre los signos, la realidad y los conceptos. Sin embargo, en las partes invariables, cuya función lógica se alcanza en la relación entre partes/términos de la oración (sesgo estructural del planteamiento, aunque más por su vinculación con la macroestructura funcional y de enfoque empirista), lo que pone de relieve el cambio de criterio hacia la perspectiva sintáctica o sintáctico-colocacional.

Sin duda alguna, se aprecia en la teoría gramatical de Espinosa un encuadre doctrinal que ya hemos podido analizar en otros autores escolares (Gámez Marín para Uruguay o Próspero González para Colombia):

Según Roig (1980: 70) escribió el prólogo y notas a la Gramática latina y escritos complementarios de Andrés Bello, en Obras completas de Bello (1958, tomo VIII, I-XCVIII). 
a) la macroestructura teórica se articula de forma coherente sobre los polos del análisis gramatical y lógico, con un mayor peso de lo gramatical (lingüístico) que lo estrictamente lógico, aunque este no deja de tener su presencia. Se enmarca, pues, de forma exacta en la periodización de la tensión lógico-gramatical que ya expusimos en Calero-Zamorano (2010);

b) la microestructura de la teoría se organiza de forma vaga sobre conceptos muy repetidos, sin coherencia metodológica en las definiciones (una nota bastante general de la gramática pre-estructural) y donde el hibridismo o, en algún caso, el eclecticismo (pues se observan ideas originales) son las notas dominantes. Esto provoca que el canon histórico sea de difícil precisión.

Lo que parece claro es que el hecho de primar la macroestructura sobre la microestructura, en la organización teórica de la gramática, pone de relieve los objetivos que el autor se plantea y que podemos resumir, según el análisis realizado, en tres:

a) propedéutica para la enseñanza de las lenguas clásicas, acorde con la actividad docente de Espinosa y fiel a un tópico que encontramos ya en el Prólogo a la Gramática castellana de Nebrija, lo que podría poner de manifiesto su sello tradicionalista vernáculo;

b) didácticos o, más específicamente, formativos. Espinosa plantea un texto con una clara intención formativa (integral ${ }^{12}$ ) del alumnado, perfectamente coherente con sus ideas en materia pedagógica, de ahí que el plan de la obra (macroestructura) esté bien diseñado, aunque internamente se perciban vacilaciones e incoherencias (por mezclas) técnicas:

[...] frente a una educación secundaria donde predomina el enciclopedismo, la instrucción, la pura transmisión de conocimientos y la memorización de estos, la opción de Aurelio Espinosa es por un bachillerato humanístico en el que predomina la formación, se propicia el clima y se utilizan los medios para el desarrollo armónico de la personalidad y, en definitiva, se forman mujeres y hombres seguros de sí mismos y decididos a servir a la comunidad, a dar y a darse con un hondo sentido patriótico (Corrales 2006: 17).

c) confianza en una práctica o método, el del análisis. El origen racionalista de este doble nivel de estudio (análisis lógico y gramatical) se respeta de forma cabal, sobre todo, si tenemos en cuenta que nos encontramos ante una obra de 1949. El análisis se afinca en la gramática escolar, surge de la importancia del doble nivel del racionalismo, de la importancia que este movimiento otorga a la sintaxis y se perpetúa de forma, incluso ajena, al desarrollo teórico de la lingüística.

Estas razones creemos que justifican la disparidad entre macroestructura y microestructura, sobre todo, si, además, tenemos en cuenta que Espinosa, a través de otros textos de corte gramatical (Corrales 2006: 75-126 $6^{13}$ y 127-146 ${ }^{14}$ ) plantea

12 Considera Espinosa que lo importante en la educación del niño no es tanto la transmisión de conocimientos, sino su formación integral (aquí se halla una verdadera filosofía de la educación) (Corrales 2006: 16).

13 "Acerca de la revisión de la gramática de la lengua española": Memorandum de la Academia Ecuatoriana al II Congreso de Academias de la Lengua acerca de la revisión de la Gramática de la Lengua Española. Ponencia de la Academia Ecuatoriana de la Lengua. Este Memorandum fue primeramente editado en Quito como opúsculo (Quito, Ed. Tirso de Molina, 1956), y extractado después en la Memoria del Segundo Congreso de Academias de la Lengua Española, Madrid, 1956, pp. 88-111.

14 "Teoría de las partes de la oración": Ponencia presentada al I Congreso de Academias de la Lengua Española, 
una metodología de corte lógico-funcional de notable coherencia. Nos referimos a dos textos en los que Espinosa trabajó y co-redactó: "Teoría sobre las partes de la oración" (1951 y publicado en 1952) y "Acerca de la revisión de la gramática de la lengua española" (1956).

En la "Teoría de las partes de la oración" de 1952 Espinosa plantea una concepción de la lengua como un organismo vivo, de honda tradición desde finales del XIX. Y con excelente criterio señala que a la hora de establecer una teoría gramatical conviene deslindar "dos actitudes posibles que dictan procedimientos distintos y a veces encontrados" (128): la del lingüista y la del pedagogo. Y señala de forma algo artificial que "la Gramática de la Academia se ubica en un plano intermedio" (130). Este criterio doble que plantea el autor en la ponencia de 1952 aporta, en gran medida, las claves de interpretación de su aparente incoherencia en el Resumen sintético y la búsqueda de coherencia (criterio único de definición, planteamiento metodológico serio, etc.) en los escritos de la serie textual-gramatical (Hassler 2002) que analizamos.

En coherencia con la macroestructura del Resumen sintético (1949) gramatical parece ser sinónimo de semántico-morfológico y lógico sinónimo de sintácticofuncional. Espinosa afirma que, en el análisis gramatical, apuesta por el criterio de la naturaleza ("pero entendiendo éste [sic] término, no en su acepción vulgar de "esencia y propiedad característica de cada ser", sino con el sentido que tiene en la filosofía perenne, a saber, de "esencia en cuanto principio de operación"” [134]), dada la dificultad de los criterios de la significación, la forma y la función. En el criterio de la naturaleza "entran en juego simultánea e indivisiblemente la significación y la función u oficio gramatical y lógico" (Corrales 2006: 134). Y más adelante afirma:

Por tanto, la naturaleza de las palabras, es decir, su esencia en cuanto operante, o, en términos gramaticales, su significación en cuanto incluye y expresa una relación determinada [=relación gramatical], es el criterio único para la clasificación de las mismas en partes de la oración. De las dos nociones que en el término naturaleza así se unifican, la más importante para el efecto de la clasificación es el oficio. Por esto predomina en casi todas las definiciones, excepto en las del sustantivo, del verbo y de la interjección (135)

Si en algún caso concreto la definición por la naturaleza ${ }^{15}$ falla se debe a anomalías que son propias de la lengua, con el fin de darle viveza y dinamismo. Son cuatro las anomalías que explica Espinosa: homofonías (=homonimia paradigmática, ej. solar, que es verbo, sustantivo y adjetivo), locuciones (perífrasis de todo tipo: verbal, sustantiva, adverbial, etc.), intercambio (cambio de función de una palabra: ej. verbo usado como sustantivo) y cumulación (una categoría tiene dos oficios: $n i=y$ no).

Por su parte, en la ponencia de 1956 Espinosa parece situarse en un planteamiento filosófico-lingüístico que supone una ecléctica aplicación del método de análisis lógico y análisis gramatical. La orientación teórica podría encuadrarse en el espiritualismo mitigado de Laromiguière y, en España, Arbolí o Avendaño. Este eclecticismo de raíz racionalista pone de relieve que el conocimiento de la lengua (el "lenguaje" en su terminología) se basa en dos criterios, que se desarrollan a través de dos métodos:

celebrado en México del 23 de abril al 6 de mayo de 1951. Publicado en Memoria del Primer Congreso de Academias de la Lengua Española celebrado en México del 23 de abril al 6 de mayo de 1951, México, 1952.

15 El criterio de la naturaleza es igual a criterio sintáctico-semántico o semántico-funcional. 
a) criterio filosófico o de significación absoluta (podría ser el análisis lógico de 1949), que define las categorías en tanto que unidades individuales a partir del concepto de la filosofía escolástica de naturaleza. La influencia de Aristóteles y los modistae en este punto es muy marcada. El isomorfismo ("correspondencias" lo llama Espinosa) es clave: modi - realidad/concepto/signos.

b) criterio sintáctico (posible análisis gramatical de 1949), que define las categorías en tanto que partes de un conjunto (incipiente estructuralismo). En la base de este planteamiento se percibe la huella de Bello, Benot o Brunot, canon que el propio Espinosa cita. Parece querer romper nuestro tratadista con la tradición de la gramática general (una vía de análisis del lenguaje según Espinosa) y la tradición empirista del uso (la otra vía). Nuestro autor apuesta por el eclecticismo. Este mismo eclecticismo pero empapado de pedagogía es el que percibimos en el Resumen sintético.

Parece que este planteamiento teórico se adopta por varios motivos: a) didácticos (los niños necesitan de un procedimiento de adquisición de la lengua, L1 y L2, distinto a los adolescentes y universitarios); b) científicos (un criterio homogéneo nos permite un conocimiento acertado de la realidad analizada); c) propedéuticos (para una posible aplicación a la doctrina académica, a la que critica y a la que le recomienda que adopte su punto de vista).

Dos aspectos resultan interesantes para la historificación de las ideas lingüísticas en América, en relación con algunos estudios ya publicados:

a) La revalorización de la figura de Benot. Encontramos en Espinosa un nuevo ejemplo de cómo la obra del intelectual gaditano fue leída y difundida en el continente americano. En el caso de Uruguay ya intentamos demostrar su influencia en los diversos niveles educativos (Zamorano Aguilar 2005 y Zamorano-Montoro del Arco 2010). En este caso, para Ecuador, encontramos un ejemplo de anti-canon o canon negativo en lo que a Benot se refiere. Espinosa afirma que Benot, en su afán iconoclasta con la terminología y planteamiento funcional, no explica, en realidad, en sus tres tomos (de la Arquitectura) la naturaleza funcional de la lengua. En cambio, a pesar de recibir críticas también, se perciben como más aceptados por Espinosa algunos gramáticos de su orientación teórica: Bello o, en otro extremos, Robles Dégano, ambos, por ejemplo, en lo que se refiere a la concepción del pronombre.

b) Presencia de canon no hispánico, aunque negativo también: Ferdinand Brunot y su obra La pensée et la langue (1927) a la que cita profusamente y cuyo planteamiento general funcional acepta Espinosa, pero no el proceso de demostración de las hipótesis:

Los segundos [se refiere a Benot y a Brunot], gramáticos de mentalidad realista, extreman las cosas por el otro lado, desentendiéndose de toda disquisición de carácter universal y limitándose deliberadamente a los hechos del lenguaje tal como se presenta éste en el uso corriente de los que lo hablan y escriben, tomando en bloque sus complejidades, sin desmenuzarlas ni averiguar su composición (Corrales 2006: 99).

Resulta interesante cómo la tradición logicista (ya derivada hacia una teoría de la morfosintaxis de las lenguas), representada por Espinosa, critica y ve con desconfianza los primeros vestigios (más allá de las intuiciones neogramáticas) de funcionalismo y de acercamiento a los datos empíricos y al método inductivo, cuyo paradigma se afincará en el estructuralismo, al menos, en la primera mitad del siglo XX, aunque en 
sus inicios saussureanos sea más formalista y con huellas de funcionalismo sólo en la escuela praguense.

\section{SíNTESIS Y CONCLUSIONES}

En este artículo hemos intentado demostrar cómo la historificación de las ideas lingüísticas en América puede suponer una reestructuración y, casi siempre, una ampliación de la historia de las ideas lingüísticas españolas, lo que revela su importancia como objeto de estudio reciente de la historiografía de la lingüística.

En este caso, nos hemos acercado a una obra de corte pedagógico, donde los fines didácticos y la trasposición de la teoría para cumplir esos fines se llevan a cabo de forma singular y, en varios sentidos, original. Desde esta perspectiva, el Resumen de Espinosa es un ejemplo más de la aplicación práctica (que defendieran Du Marsais y Locke) de la teoría racionalista, aunque predominantemente ecléctica, donde incluso Port-Royal y los modistae se dejan sentir. El canon histórico de lecturas que se manifiesta en la microestructura teórica del Resumen de Espinosa Pólit es fiel a una práctica pedagógica y, sobre todo, formativa, del valor que se otorga al análisis gramatical y lógico en el desarrollo del pensamiento, del lenguaje $\mathrm{y}$, consecuentemente, en el aprendizaje de las lenguas nacionales y, como fin último, de las lenguas clásicas. Esa etapa de trasvase de lo lógico a lo lingüístico, que en Calero-Zamorano (2010) fijábamos en torno a 1880-1882 y terminábamos en 1939, podría extenderse hasta la década de los 50 con una simbiosis de tradicionalismo racionalista (no nebrisense, ni academicista, como resulta frecuente en nuestra historia gramatical) y de funcionalismo inicipiente.

El pensamiento gramatical de Espinosa Pólit resulta singular, además, porque nos encontramos ante un intelectual, un académico, un estudioso de la literatura, formado en Europa, de formación religiosa jesuítica y conservadora (más apegado a la tradición racionalista pura o, incluso de tipo mitigado, que a los ideólogos), que confecciona un texto (de equilibrio entre teoría y práctica y de uso en las escuelas de su congregación) de coherente macroestructura teórica (como otros en la tradición hispánica: española e hispanoamericana) y de vaga microestructura, con un canon ecléctico de lecturas fruto de la transposición didáctica a la que somete a la teoría, pero cuya raíz última (según se desprende de sus ideas teóricas plasmadas en otros textos de la serie gramatical) en una coherencia de método (que fija en la naturaleza de las categorías como esencia en cuanto principio de operación), donde se establece una relación lógico-gramatical que desemboca en tres binomios relativamente modernos y de cierta profundidad teórica: estructura profundaestructura superficial, universalismo-relativismo y criterio sintáctico-funcional frente a semántico-morfológico.

La recepción de las ideas lingüísticas en América y, en este caso, en Ecuador, deja ver un asentamiento específico de tradición racionalista (frente a la académica predominante, a pesar de que Espinosa era correspondiente de la RAE y reclamaba este enfoque teórico para la obra de la docta Institución), de sabor ecléctico, de aprovechamiento de lo lógico hacia lo sintáctico, entendido este, según hemos indicado también, como funcional, profundo y de tendencia universalista, donde se realiza una crítica al funcionalismo benotiano, más empirista que el planteado por Espinosa, y a la teoría brunotiana también, como ejemplos de un paradigma 
realista; y, por el contrario, una cierta ponderación del Bello más racionalista o, incluso, de Robles Dégano, entre otros. Esta recepción de ideas lingüísticas en el Ecuador de las primeras décadas del siglo XX convierte a Aurelio Espinosa Pólit en una pieza historiográficamente relevante $\mathrm{o}$, al menos, que debe tenerse en cuenta en la reconstrucción de la historia de la lingüística española, a la vez que supone, una vez más, una revalorización de la gramática escolar como objeto de estudio científico y pertinente en el desarrollo de las ideas lingüísticas generales.

\section{OBRAS CITADAS}

AA.VV. 1961. "Padre Aurelio Espinosa Pólit, S. I.”. Thesaurus XVI, 1. 270-271.

Álvarez Martínez, María Ángeles. 1994. La gramática española en América. La Laguna: Servicio de Publicaciones de la Universidad.

Avilés Pino, Efrén. s.f. "Espinoza Pólit, Aurelio". En líne; disponible en http: //www. enciclopediadelecuador.com. (Fecha consulta: 7 de noviembre de 2011).

Brekle, Hebert E. 1986. "What is History of Linguistics and to what end is it produced? A didactic approach". En Th. Bynon y F. R. Palmer, Eds., Studies in the history of Western Linguistics: in honour of R. H. Robins. Cambridge: Cambridge University Press. 1-10.

Calero Vaquera, María Luisa. 1986. Historia de la gramática española (1847-1920). De A. Bello a R. Lenz. Madrid: Gredos.

2004. "Métodos de enseñanza gramatical en la tradición: propuesta de nueva disciplina". C. Corrales Zumbado et al., Eds., Nuevas aportaciones a la Historiografía Lingüística. Actas del IV Congreso Internacional de la Sociedad Española de Historiografía Lingüística. Madrid: Arco/Libros. Vol. I. 317-326.

. 2008a. “Análisis lógico y análisis gramatical en la tradición española: hacia una (r) evolución de la sintaxis”. En M. Maquieira y Ma D. Martínez, Eds. Gramma-Temas 3. España y Portugal en la tradición gramatical. León: SPU. 11-42.

2008b. "Una muestra de la presencia en Hispanoamérica del análisis lógico y gramatical: el Tratado (Buenos Aires, 1880) de V. García Aguilera”. Ed.Uco 3: 27-39. . 2009a. "Lo que la sintaxis debe a la filosofía". En Montserrat Veyrat Rigat et al., La lingüística como reto epistemológico y como acción social: estudios dedicados a Ángel López García con ocasión de su sexagésimo aniversario. Vol. 1. Madrid: Arco/Libros. 25-36 . 2009b. "Apuntes sobre el Curso gradual de gramática castellana (c. 1930) de José Hidalgo Martínez y su lugar en la tradición escolar argentina”. Revista Argentina de Historiografía Lingüística 1, 2: 151-174.

2010. "Sintaxis y gramática escolar en la España del siglo XIX: su proyección en Hispanoamérica”. C. Assunção, G. Fernandes, M. Loureiro, Eds., Ideias Linguísticas na Península Ibérica. Münster: Nodus Publikationen. 67-84.

Calero Vaquera, María Luisa y Alfonso Zamorano Aguilar. 2010. "El término ‘análisis’ en las gramáticas de la tradición hispánica. Estudio metalingüístico”. V. Eilers, K. Süselbeck y K. Wieland, Eds., Aspectos del desarrollo de la lingüística española a través de los siglos. Hamburg: Helmut Buske Verlag (RomGG Beiheft 18). 13-29.

Chervel, André. 1977. Histoire de la grammaire scolaire... et il fallut apprendre à écrire à tous les petits Français. Paris: Payot.

Chevallard, Yves. 1991 [1985]. La transposición didáctica. Del saber sabio al saber enseñado. Buenos Aires: Ed. Aique.

Condillac, Étienne Bonnot de. 1789 [1775]. Cours d'étude pour l'instruction du Prince de Parme, t. I: Grammaire. Genève/Avignon: Chez Fr. Dufart/Chez Joly.

Corrales Pascual, Manuel. 2006. Pensamiento de Aurelio Espinosa Pólit. Quito: Banco Central del Ecuador. 
Delgado Criado, Bartolomé. coord. 1994. Historia de la educación en España y América. La educación en la España contemporánea (1789-1975). Vol. 3. Madrid: S.M.

Espinosa Pólit, Aurelio. 1996. Dieciocho clases de literatura: curso intensivo de verano para profesores de castellano y literatura, oficiales y particulares: agosto-septiembre 1945. Manuel Corrales Pascual, Ed. Quito: Pontificia Universidad Católica del Ecuador.

Espinosa Pólit, Aurelio y Espinosa Pólit, José. 1949. Resumen sintético de análisis gramatical y lógico. Quito: Editorial Ecuatoriana.

García Folgado, María José. 2008. "Aproximaciones a la enseñanza del análisis: los Principios del análisis lójico de Ramón Merino (1848)”. Comunicación presentada a ICHOLS XI (Potsdam, 28 agosto-2 septiembre de 2008).

2010. "Estudiar la gramática bajo un orden analítico: la obra de Felipe Senillosa (1817)". Ma T. Encinas et al., Comps., Ars Longa. Diez años de AJIHLE. Vol. 2. Buenos Aires: Ediciones Voces del Sur. 663-678

García Folgado, María José y Esteban T. Montoro del Arco. 2008. "La enseñanza del análisis lógico y gramatical en el siglo XIX: legislación e ideas pedagógicas”. Comunicación presentada al XV Congreso de la ALFAL (Montevideo, Uruguay, 18-21 de agosto de 2008).

García Muñoz, Ana Elizabeth. 2003. "Estudio del conocimiento de las carreras que se ofertan en el país y la demanda de ellos por parte de los futuros bachilleres de la ciudad de Guayaquil". Tesis de Grado inédita. Escuela Superior Politécnica del Litoral. En línea; disponible en: http: //www.dspace.espol.edu.ec/handle/123456789/5787 (Fecha de consulta: 1 de noviembre de 2011).

García Yebra, Valentín. 1962. “A. E. P., traductor de poetas clásicos”. Arbor 52: 286-312.

Hassler, Gerda. 2002. "Textos de referencia y conceptos en las teorías lingüísticas de los siglos XVII y XVIII”. Miguel Ángel Esparza [et al.]. eds. Actas del III Congreso Internacional de la SEHL. Hamburg: Helmut Buske Verlag. 559-585.

Kovacci, O. 1991. "Estado actual y perspectivas de los estudios gramaticales en Hispanoamérica”. Simposio Internacional de Investigadores de la Lengua Española. Sevilla: Pabellón de España.

Lope Blanch, Juan Manuel. 1989. "La investigación lingüística en Hispanoamérica”. Estudios de lingüística hispanoamericana. México: UNAM. 65-84.

López Ferrero, Carmen. 1997. La gramática en la enseñanza secundaria. Nociones de irregularidad y dependencia en las gramáticas pedagógicas de la lengua española (1901-1980): estudio de su transposición didáctica. Tesis doctoral inédita. Barcelona: Universitat de Barcelona.

Martínez Navarro, Isabel. 1996. La gramática en la enseñanza de la lengua española. Murcia: DM.

Montoro del Arco, Esteban T. y Alfonso Zamorano Aguilar. 2010. "Notas sobre teoría sintáctica y fraseológica en manuales uruguayos de gramática escolar”. In: $\mathrm{M}^{\mathrm{a}} \mathrm{T}$. Encinas et al. (comps.), Ars Longa. Diez años de AJIHLE. Vol. 2. 739-756. Buenos Aires: Ediciones Voces del Sur.

Parodi, Claudia. 1981. La investigación lingüística en México (1970-1980). México: UNAM.

Rabanales, Ambrosio. 1978. "Repercusión de las corrientes lingüísticas contemporáneas en Iberoamérica”. Boletín de Filología de la Universidad de Chile 29: 219-257.

Roig, Arturo Andrés. 1980. Aurelio Espinosa Pólit: humanista y filósofo. Quito: Ediciones de la Universidad Católica.

Sinner, Carsten. 2009. "Las gramática francesas como fundamento, modelo e inspiración del análisis lógico y el análisis gramatical en España". Revue de Linguistique Romane 73. 427-460.

. 2010. "Aproximación al análisis lógico en Chile: Julio Meza". Boletín de la Sociedad Española de Historiografía Lingüística 7: 173-184. 
Sueiro Justel, Joaquín. 2002. La política lingüística española en América y Filipinas (siglos $X V I-X I X)$. Lugo: Tris Tram.

Varo, C. 1961. "Evocación y elogio de un humanista ecuatoriano". Razie 164. 117-124.

Villalba, J. y J. Baptista. 2011. "Espinosa Pólit, en Ecuador", http: //www.euskalnet.net/ laviana/monografias/espinosa.htm (Fecha de consulta: 3 de noviembre de 2011).

Zamorano Aguilar, Alfonso. 2005. "Historia de la gramática española en América (I) Uruguay. A propósito de Francisco Gámez Marín (1868-1932)”. Revista de Lingüística Teórica y Aplicada 43: 2. 85-118.

. 2008a. "Historia de la gramática española en América (II). Uruguay. Los manuales escolares de R. Abadíe Soriano y H. Zarrilli (1924, 1937)”. Ed.Uco 3: 71-100. . 2008b. "Ideología, lengua y enseñanza en la España del XIX: la teoría gramatical de Ángel María Terradillos”. Lingüística 20: 49-98.

. 2009. "Epihistoriografía de la lingüística y teoría del canon". Montserrat Veyrat

Rigat et al. eds. La lingüística como reto epistemológico y como acción social: estudios dedicados a Ángel López García con ocasión de su sexagésimo aniversario. Vol. 1. Madrid: Arco/Libros. 209-220.

. 2010a. "Análisis lógico y análisis gramatical en Colombia (s. XX): la teoría lingüística de Próspero González Ruiz". RAHL: Revista Argentina de Historiografía Lingüística 2: 2: 125-143.

. 2010b. "Los principios gramaticales del presbítero colombiano Rafael Celedón (1833-1902): canon y fundamentos teóricos”. C. Assunção, G. Fernandes, M. Loureiro, Eds. Ideias Linguísticas na Península Ibérica. Vol. 2. Münster: Nodus Publikationen. 867-883. 